\title{
JMR Abstracts
}

Editor-in-Chief: Robert A. Laudise - Associate Editors: Shigeyuki Sōmiya, Heinrich J. Wollenberger

\section{TABLE OF CONTENTS}

\section{December JMR issue includes Year-End Indexes for Authors; Materials; and Contents by Topic}

\section{COMMUNICATIONS}

Directional solidification by appropriate chemically active single crystal seed: An alternate way of generating large superconducting 123 single domain

R. Cloots, Fr. Auguste, A. Rulmont, N. Vandewalle, M. Ausloos

The standard molar enthalpies of formation of $\alpha-\mathrm{Si}_{3} \mathrm{~N}_{4}$ and $\beta-\mathrm{Si}_{3} \mathrm{~N}_{4}$ by combustion calorimetry in fluorine, and the enthalpy of the $\alpha-$ to- $\beta$ transition at the temperature $298.15 \mathrm{~K}$

P.A.G. O'Hare, I. Tomaszkiewicz, H.J. Seifert

Laser micromachining of $\mathrm{Al}_{2} \mathrm{O}_{3}$-TiC ceramics

V. Oliveira, R. Vilar, O. Conde, P. Freitas

Czochralski growth of $\mathrm{Yb}^{3+}$ and $\mathrm{Pr}^{3+}$ doped Ca-fluoroapatite

A. Caprez, P. Mikhail, C. Schwecke, J. Hulliger

\section{ARTICLES}

Superconducting properties and structural stability of $\mathrm{Bi}_{2} \mathrm{Sr}_{2} \mathrm{CaCu}_{2} \mathrm{O}_{8+\delta}$ compound prepared by electrochemical reduction in protogenic electrolyte

M. Matsuda, H. Tamada, K. Yamashita, T. Umegaki, M. Miyake

Scanning and transmission electron microscopies of single-crystal silicon microworn/machined using atomic force microscopy

V.N. Koinkar, B. Bhushan

Microwave assisted synthesis of technologically important transition metal silicides

B. Vaidhyanathan, K.J. Rao

A time-resolved x-ray difiraction study of $\mathrm{Ti}_{5} \mathrm{Si}_{3}$ product formation during combustion synthesis

C.R. Kachelmyer, I.0. Khomenko, A.S. Rogachev, A. Varma

Study of fluoride induced dissimilar metal corrosion in a microelectromechanical system

J. Prasad, O.M.R. Chyan, J-J. Chen, M. Liu, L. Chen, F. Xu

Improving the wear resistance of Al-Si alloy by ion implantation Y. Itoh, H. Azuma, A. Itoh, T. Hioki

Calculated phase diagrams for activated low pressure diamond growth from C-H, C-O and C-H-O systems

J-T. Wang, Y-Z. Wan, D.W. Zhang, Z-J. Liu, Z-Q. Huang

Solid-state mechanical alloying of plastic crystals

J. Font, J. Muntasell, E. Cesari, J. Pons
Preparation of fine-grained $\mathrm{MgO}$ and $\mathrm{Gd}_{2} \mathrm{O}_{3}$ stabilized $\mathrm{ZrO}_{2}$ thin films by electron beam physical vapor deposition co-evaporation F. Tcheliebou, M. Boulouz, A. Boyer

Microstructure of liquid phase sintered superplastic silicon carbide ceramics

C-M. Wang, M. Mitomo, H. Emoto

Ultrasound driven aggregation and surface silanol modification in amorphous silica microspheres

S. Ramesh, Y. Koltypin, A. Gedanken

Hydrothermal synthesis and sintering of nickel and manganese-zinc ferrites

A. Dias, V.T.L. Buono

Preparation and characterization of nanosized zirconium (hydrous) oxide particles

L.A. Perez-Maqueda, E. Matijević

The effect of $\mathrm{Cr}$ and $\mathrm{La}$ on $\mathrm{MgTiO}_{3}$ and $\mathrm{MgTiO}_{3}-\mathrm{CaTiO}_{3}$ microwave dielectric ceramics

V.M. Ferreira, F. Azough, R. Freer, J.L. Baptista

Alumina platelet reinforced reaction bonded aluminum oxide composites: Textured and random

L. An, S. Wu, H.M. Chan, M.P. Harmer, D.G. Brandon

Failure behavior of alumina and alumina/silicon carbide nanocomposites with natural and artificial flaws

F. Meschke, P. Alves-Riccardo, G.A. Schneider, N. Claussen

$\mathrm{Ag}: \mathrm{Sb}$ and $\mathrm{Sb}: \mathrm{Ag}$ implantations into high purity silica

T.S. Anderson, R.H. Magruder III, D.L. Kinser, J.E. Wittig, R.A. Zuhr, D.K. Thomas

In situ formation of $\mathrm{MoSi}_{2}$-SiC through reaction of $\mathrm{SiO}_{2}$ or $\mathrm{Si}_{3} \mathrm{~N}_{4}$ with Mo and carbon

R.V. Krishnarao, V.V. Ramarao, Y.R. Mahajan

A descriptive model linking possible formation mechanisms for graphite-encapsulated nanocrystals to processing parameters B.R. Elliott, J.J. Host, V.P. Dravid, M.H. Teng, J-H. Hwang

The mechanical behavior of a passivating surface under potentiostatic control

D.F. Bahr, J.C. Nelson, N.I. Tymiak, W.W. Gerberich

Insights into the ion-assisted nucleation of diamond on silicon S.P. McGinnis, M.A. Kelly, S.B. Hagström 
Interdiffusions and reactions in $\mathrm{Cu} / \mathrm{TiN} / \mathrm{Ti} / \mathrm{Si}$ and $\mathrm{Cu} / \mathrm{TiN} / \mathrm{Ti} / \mathrm{SiO}_{2} / \mathrm{Si}$ multilayer structures

S-K. Rha, W-J. Lee, S-Y. Lee, D-W. Kim, C-O. Park, S-S. Chun

Diamond nucleation on smooth $\mathrm{Si}_{3} \mathrm{~N}_{\mathbf{4}}$-coaled substrate

N. Xu, Z. Zheng, Y. Du

Pulsed laser deposition of carbon nitride thin films in nitrogen gas ambient

M. Okoshi, H. Kumagai, K. Toyoda
A study on magnesium diffusion inio $\mathrm{LiNhO}_{3}$ single crystal by $\mathrm{x}$-ray diffraction, differential thermal analysis and scanning electron microscopy

W. Que, S. Lim, X. Yao, A.Q. Liu

Influence of nanostructure size on the Iuminescence behavior of silicon nanoparticle thin films

A.A. Seraphin, E. Werwa, K.D. Kolenbrander

A novel polymer electrolyte based on oligo(ethylene glycol) 600 , $\mathrm{K}_{2} \mathrm{PdCl}_{4}$ and $\mathrm{K}_{3} \mathrm{Fe}(\mathrm{CN})_{6}$

V. Di Noto

\section{ABSTRACTS}

\section{COMMUNICATIONS}

Directional solidification by appropriate chemically active single crystal seed: An alternate way of generating large superconducting 123 single domain

R. Cloots, Fr. Auguste, A. Rulmont, N. Vandewalle, M. Ausloos (University of Liège)

$A \mathrm{Dy}_{2} \mathrm{O}_{3}$ single crystal has been used as a seed for the growth of isothermally melt-textured Dy-123 material. The nucleation-controlled step has been observed to be related to the heterogeneous nucleation of 211 particles at the surface of the dysprosium oxide single crystal. The subsequent growth mode seems to be controlled by a high concentration gradient of dysprosium in the liquid phase. This leads to a directional solidification process of the 123 phase. The size of the 211 particles seems to decrease as the distance from the dysprosium oxide single crystal increases.

Order No.: JA712-001

(C) 1997 MRS

The standard molar enthalpies of formation of $\alpha-\mathrm{Si}_{3} \mathrm{~N}_{4}$ and $\beta-\mathrm{Si}_{3} \mathrm{~N}_{4}$ by combustion calorimetry in fluorine, and the enthalpy of the $\alpha$-to- $\beta$ transition at the temperature $298.15 \mathrm{~K}$

P.A.G. O'Hare*, I. Tomaszkiewicz', H.J. Seifert ${ }^{\#}$

( ${ }^{*}$ National Institute of Standards and Technology, +Polish Academy of Sciences, ${ }^{\#}$ Max-Planck-Institut für Metallforschung)

The standard molar enthalpies of formation $\Delta_{\mathrm{f}} \mathrm{H}_{\mathrm{m}}^{\circ}$ of $\alpha-\mathrm{Si}_{3} \mathrm{~N}_{4}$ and $\beta-\mathrm{Si}_{3} \mathrm{~N}_{4}$ have been determined by fluorine combustion calorimetry: $\Delta_{\mathrm{f}} \mathrm{H}_{\mathrm{m}}^{\circ}\left(\mathrm{Si}_{3} \mathrm{~N}_{4}, \mathrm{Cr}, \alpha, 298.15 \mathrm{~K}\right)=-(828.9 \pm 3.4) \mathrm{kJ} \cdot \mathrm{mol}^{-1}$ and $\Delta_{\mathrm{f}} \mathrm{H}_{\mathrm{m}}^{\circ}\left(\mathrm{Si}_{3} \mathrm{~N}_{4}\right.$, cr, $\beta, 298.15 \mathrm{~K})=-(827.8 \pm 2.5) \mathrm{kJ} \cdot \mathrm{mol}^{-1}$. These results indicate that the enthalpy of the $\alpha$-to- $\beta$ transition, approximately $(1 \pm 4) \mathrm{kJ} \cdot \mathrm{mol}^{-1}$, is negligible within experimental uncertainty.

Order No.: JA712-002

(C) 1997 MRS

\section{Laser micromachining of $\mathrm{Al}_{2} \mathrm{O}_{3}$-TiC ceramics}

V. Oliveira*, R. Vilar*, O. Conde ${ }^{*}$, P. Freitas*

('Instituto Superior Técnico, +University of Lisbon)

$\mathrm{Al}_{2} \mathrm{O}_{3}-34 \mathrm{wt} \% \mathrm{TiC}$ ceramics have been machined with a $\mathrm{KrF}(248 \mathrm{~nm})$ excimer laser under normal atmosphere. In the initial steps of the irradiation process both the roughness and the removal rate present a strong variation with the number of pulses. After approximately 200 pulses the process reaches a stationary regime where the roughness and the removal rate become constant. Characterization of the machined areas by scanning electron microscopy showed that the variations in roughness and removal rate are related to the evolution of the samples' surface topography. Also, as a consequence of laser irradiation $\mathrm{TiC}$ and $\mathrm{Al}_{2} \mathrm{O}_{3}$ are partially transformed into $\mathrm{TiO}_{2}, \mathrm{TiC}_{07} \mathrm{~N}_{0.3}$ and an $\mathrm{Al}-\mathrm{Ti}$ solid solution.

Order No.: JA712-003
Czochralski growth of $\mathrm{Yb}^{3+}$ and $\mathrm{Pr}^{3+}$ doped Ca-fluoroapatite

A. Caprez, P. Mikhail, C. Schwecke, J. Hulliger

(University of Berne)

Pure, $\mathrm{Pr}^{3+}$ and $\mathrm{Yb}^{3+}$ doped Ca-fluoroapatite (Ca-FAP) crystals were grown by the Czochralski method. The effective distribution coefficient $k_{\text {eff }}$ for $\mathrm{Yb}^{3+}$ was 0.5 . For $\mathrm{Pr}^{3+}$ a very high $\mathrm{k}_{\text {eff }}$ of 1.4 was obtained. Values for $\mathrm{k}_{\text {eff }}$ were discussed in terms of an elastic model accounting for the strain energy originating from the difference in the size of $\mathrm{Ln}^{3+}$ ions. The $\mathrm{Ln}^{3+}$ concentrations were measured by absorbance spectroscopy, by inductively coupled plasma optical emission spectroscopy and by electron microprobe analyses.

Order No.: JA712-004

C 1997 MRS

\section{ARTICLES}

Superconducling properties and structural stability of $\mathrm{Bi}_{2} \mathrm{Sr}_{2} \mathrm{CaCu}_{2} \mathrm{O}_{8+\delta}$ compound prepared by electrochemical reduction in protogenic electrolyte

M. Matsuda ${ }^{\star}$, H. Tamada*, K. Yamashita ${ }^{\star}$, T. Umegaki*, M. Miyake ${ }^{+}$ ( ${ }^{*}$ Tokyo Metropolitan University, + Okayama University)

Superconducting $\mathrm{Bi}_{2} \mathrm{Sr}_{2} \mathrm{CaCu}_{2} \mathrm{O}_{8+\delta}$ (Bi-2212) compound was electrochemically reduced in a protogenic electrolyte of benzoic acid dissolved in acetone. The critical temperatures $\left(T_{c}\right)$ of the reduced $\mathrm{Bi}-2212$ were enhanced from $75 \mathrm{~K}$ up to $\sim 90 \mathrm{~K}$, which were reportedly the highest value of $\mathrm{Bi}-2212$ superconductor. In spite of the enhancement of $T_{C}$, a diamagnetism of Bi-2212 was weakened after the reduction. This phenomenon was discussed in terms of the flux penetration depth. The electrochemicaily reduced $\mathrm{Bi}-2212$ had a different structural stability from a partly oxygenremoved Bi-2212 which was prepared by annealing in reducing atmospheres. It was considered that these results were altributed to injection of protons from the benzoic acid into the Bi-2212 structure.

Order No.: JA712-005

(C) 1997 MRS

Scanning and transmission electron microscopies of single-crystal silicon microwom/machined using atomic force microscopy

V.N. Koinkar, B. Bhushan

(The Ohio State University)

Atomic force microscopy (AFM) is commonly used for microwear/ machining studies of materials at very light loads. To understand material removal mechanism on the microscale, scanning electron microscopy (SEM) and transmission electron microscopy (TEM) studies were conducted on the microworn/machined single-crystal silicon. SEM studies of micromachined single-crystal silicon indicate that at light loads material is removed by ploughing. Fine particulate debris is observed at light loads. At higher loads, cutting type and ribbon-like debris were observed. This debris is loose and can be easily removed by scanning with an AFM tip. 
TEM images of a wear mark generated at $40 \mu \mathrm{N}$ show bend contours in and around the wear mark, suggesting that there are residual stresses. Dislocations, cracks or any special features were not observed inside nor outside wear marks using plan-view TEM. Therefore, material is mostly removed in a brittle manner or by chipping without major dislocation activity, crack formation and phase transformation at the surface. However, presence of ribbon-like debris suggests some plastic deformation as well. Order No.: JA712-006

(C) 1997 MRS

\section{Microwave assisted synthesis of technologically important transition} metal silicides

B. Vaidhyanathan, K.J. Rao

(Indian Institute of Science)

A novel, simple, clean and fast microwave assisted method of preparing important transition metal silicides $\left(\mathrm{MoSi}_{2}, \mathrm{WSi}_{2}, \mathrm{CoSi} \mathrm{i}_{2}\right.$ and $\mathrm{TiSi}_{2}$ ) has been described. Amorphous carbon is used both as a microwave susceptor and as a preventer of oxidation.

Order No.: JA712-007

(C) 1997 MRS

A time-resolved $x$-ray diffraction study of $\mathrm{Ti}_{5} \mathrm{Si}_{3}$ product formation during combustion synthesis

C.R. Kachelmyer*, I.O. Khomenko+, A.S. Rogachev', A. Varma*

("University of Notre Dame, +Russian Academy of Science)

Time-resolved $x$-ray diffraction (TRXRD) was performed during $\mathrm{Ti}_{5} \mathrm{Si}_{3}$ synthesis by the self-propagating high-temperature synthesis mode for different Ti size fractions. It was determined that the time for product formation (ca.10 s) was independent of Ti particle size. However, the formation of $\mathrm{Ti}_{5} \mathrm{Si}_{4}$ phase occurred when relatively large titanium particles were used. A simultaneous measurement of the temperature and TRXRD allowed us to attribute the shifting of XRD peaks at high temperature to thermal expansion of the $\mathrm{Ti}_{5} \mathrm{Si}_{3}$ product. The thermal expansion coefficients differ for different crystal planes, and their numerical values compare well with those reported previously in the literature.

Order No.: JA712-008

(C) 1997 MRS

\section{Study of fluoride induced dissimilar metal corrosion in a microelectromechanical system}

J. Prasad ${ }^{*}$, O.M.R. Chyan+ J-J. Chen+, M. Liu ${ }^{+}$L. Chen ${ }^{+}$, F. Xu+

("Texas Instruments/SEMATECH, + University of North Texas)

This paper reports a study of microscopic on-chip corrosion on a $17 \mu \mathrm{m} \times 17 \mu \mathrm{m}$ microelectromechanical device. The active atmospheric corrosion occurred only on the Al-Si-Ti components which were connected directly to the Ti-W components. Adsorbed fluoride ionic species on the microelectromechanical device were found to activate the observed bimetallic corrosion on the Al-Si-Ti/Ti-W contacts. Water rinse or replacement of Ti-W by TiAl completely eliminate the active corrosion. Electro-chemical potential data confirm the dissimilar metal corrosion mechanism. Effective prevention of on-chip corrosion was achieved by the judicious design of the device components to avoid dissimilar metal contacts with large galvanic potential differences.

Order No.: JA712-009

C 1997 MRS

Improving the wear resistance of Al-Si alloy by ion implantation

Y. Itoh, H. Azuma, A. Itoh, T. Hioki

(Toyota Central R\&D Laboratories, Inc.)

The mechanical properties of ion implanted Al-Si alloy were studied using disk samples of alloy irradiated with $\mathrm{Ar}^{+}, \mathrm{B}^{+}$and $\mathrm{N}_{2}+$ ions.

Knoop hardness of ASTM 336.0 disks increased from 117 to $165 \mathrm{kgf} / \mathrm{mm}^{2}$ upon $\mathrm{N}_{2}+$ ion implantation. To measure tribological properties, lubricated ball-on-disk tests were performed using steel balls. The coefficients of friction of ion implanted disks were higher than those of unimplanted ones. Ion implantation improved the wear resistance of the disks, and in the case of $\mathrm{N}_{2}+$ ion implanted disks, the worn volume was smaller than $10^{-4} \mathrm{~mm}^{3}$
The XPS analysis for $\mathrm{N}_{2}+$ ion implanted samples revealed the formation of aluminum and silicon nitride on the sample surface. On the other hand, the cross-sectional image of the ion implanted surface showed precipitated $\mathrm{Si}$ which is held under the implanted $\mathrm{Ni}_{2}{ }^{+}$ions.

Order No.: JA712-010

(C) 1997 MRS

Calculated phase diagrams for activated low pressure diamond growth from C-H, C-O and C-H-O systems

J-T. Wang ${ }^{\star}$, Y-Z. Wan*, D.W. Zhang ${ }^{*}$, Z-J. Liu* ${ }^{*}$ Z-Q. Huang ${ }^{*}$

( ${ }^{\star}$ Fudan University, + Tongji University)

Three-dimensional temperature $(T)$ - pressure $(P)$ - composition $(X)$ phase diagrams of binary carbon-hydrogen $(\mathrm{C}-\mathrm{H})$ and carbon-oxygen $(\mathrm{C}-0)$ systems for the activated low pressure diamond growth have been calculated. Based on an approximation of linear combination between $\mathrm{C}-\mathrm{H}$ and $\mathrm{C}-\mathrm{O}$ systems, a projective ternary carbon-hydrogen-oxygen $(\mathrm{C}-\mathrm{H}-\mathrm{O})$ phase diagram has also been obtained. There is always a diamond growth region in each of these phase diagrams. Once a supply of external activating energy stops, the diamond growth region will not exist. Nearly all of the reliable experimental data reported in the literature drop into the possible diamond growth region of the calculated projective ternary $\mathrm{C}-\mathrm{H}-\mathrm{O}$ phase diagram under the conditions of $0.01-100 \mathrm{kPa}$ and above $700 \mathrm{~K}$.

Order No.: JA712-011

(c) 1997 MRS

Solid-state mechanical alloying of plastic crystals

J. Font* ${ }^{*}$, J. Muntasell ${ }^{*}$, E. Cesari ${ }^{+}$, J. Pons ${ }^{+}$

( ${ }^{*}$ Univ. Politècnica de Catalunya, +Univ. Illes Balears)

Ball milling has been used as a solid-state mechanical alloying technique in two binary systems of plastic crystals: Neopentylglycol/ Pentaglycerin (NPG/PG), showing a partial solubility in the ordered phase, and 2-amino-2-methyl-1,3-propanediol/Tris(hydroxymethyl) (AMP/TRIS) whose immiscibility in this ordered solid phase is almost total. For the AMP/TRIS system the stable state at room temperature has been reached by milling. Contrary, for NPG/PG, DSC measurements reveal that an annealing period is required after milling. These results have been compared with those of Pentaglycerin/Pentaerythritol (PG/PE) binary system, previously studied, whose miscibility is total at room temperature.

Order No.: JA712-012

(C) 1997 MRS

Preparation of fine-grained $\mathrm{MgO}$ and $\mathrm{Gd}_{2} \mathrm{O}_{3}$ stabilized $\mathrm{ZrO}_{2}$ thin films by electron beam physical vapor deposition co-evaporation

F. Tcheliebou, M. Boulouz, A. Boyer

(Université Montpellier II)

Thin films of $\mathrm{ZrO}_{2}$ doped with $\mathrm{MgO}$ and $\mathrm{Gd}_{2} \mathrm{O}_{3}, 1-1.5 \mu \mathrm{m}$ in thickness are formed onto nickel substrates by reactive thermal evaporation using a dual-hearths electron gun. X-ray diffraction patterns of the deposits show changes in the crystallographic structure and average particle size as a function of the dopant content. A mixture of monoclinic and tetragonal phases gradually disappears to the benefit of a single cubic phase with increasing dopant molar fraction. Average crystallite size deduced from diffraction line broadening decreases as the dopant content is increased. This observation is strongly confirmed by scanning electron micrographs which reveal a smooth surface topography. Fine-grained materials obtained here are interpreted in terms of high nucleation rate and kinetically limited grain growth. It appears that composition, crystallographic structure and microstructure relations are of paramount importance in $\mathrm{ZrO}_{2}$-based films prepared by electron-beam evaporation.

Order No.: JA712-013

(C) 1997 MRS

\section{Microstructure of liquid phase sintered superplastic silicon carbide} ceramics

C-M. Wang, M. Mitomo, H. Emoto

(National Institute for Research in Inorganic Materials)

Superplastic silicon carbide ceramics were fabricated at low temperatures by a liquid phase sintering very fine $\beta$-SiC powder. The microstruc- 
tural features of this material, both before and after the superplastic deformation, have been investigated by transmission electron microscopy. 'Evaluated from the point of view of phase transformation, dislocation motion, and dynamic grain growth, the materials show very stable microstructures indicating that the superplastic deformation process was dominated by the liquid phase assisted grain boundary sliding. In addition, the material is also characterized by the formation of clusters of fine SiC particles $(5-20 \mathrm{~nm})$ encapsulated in layered graphitized carbon.

Order No.: JA712-014

(C) 1997 MRS

\section{Ultrasound driven aggregation and surface silanol modification in} amorphous silica microspheres

S. Ramesh, Y. Koltypin, A. Gedanken

(Bar-Ilan University)

Post-formed, silica submicrospheres synthesized by Stober's method have been subjected to a high intensity ultrasound radiation $\left(20 \mathrm{kHz}, 100 \mathrm{~W} / \mathrm{cm}^{2}\right)$ and their size, morphology and surface silanol structure modified in-situ. The processed silica powders have been characterized by a variety of techniques, such as powder x-ray diffraction (XRD), transmission electron microscopy, dynamic light scattering (DLS), BET nitrogen adsorption and FT-IR spectroscopy. The silica microspheres formed through an irreversible sol-gel transition have been shown to aggregate by the condensation of interparticle silanols to larger particles under the influence of the shock waves emanating from an imploding cavity. The particle size as a function of sonication time passes through a maximum, suggesting the disintegration of the aggregates on longer exposure to ultrasound radiation. The sonication of dried silica microspheres in an inert dispersant decalin also led to the aggregation of microspheres to a lesser degree suggesting the deactivation of surface silanols. Infrared spectroscopic investigations suggest a disruption of the hydrogen bonded network of surface silanols. The observed morphological changes have been discussed in terms of direct effect of cavitation on well-formed spheres rather than changes in growth mechanism and capture of primary particles.

Order No.: JA712-015

(C) $1997 \mathrm{MRS}$

\section{Hydrothermal synthesis and sintering of nickel and manganese-zinc} ferrites

A. Dias, V.T.L. Buono

(Escola de Engenharia-UFMG)

The influence of the starting materials on the crystalline phases observed after hydrothermal synthesis of nickel and manganese-zinc ferrites was investigated. The combination of sulfates and sodium hydroxide showed the best results for the conditions studied. The morphological parameters of $\mathrm{MnZn}$ ferrites produced at different hydrothermal conditions $\left(110-190^{\circ} \mathrm{C}, 4-30\right.$ hours) were analyzed. Changes in lattice parameter, particle size, density, size and total volume of pores and in the surface area of the particles were analyzed as a function of temperature and processing time. The sintering process was employed in order to verify the reactivity of the hydrothermal powders at controlled atmosphere. High density and surface homogeneous ceramic bodies were obtained, without zinc volatilization. Lattice parameter variations were associated to changes in the cations distribution of the spinel during sintering.

Order No.: JA712-016

(C) 1997 MRS

Preparation and characterization of nanosized zirconium (hydrous) oxide particles

L.A. Perez-Maqueda, E. Matijević

(Clarkson University)

A method for the preparation of nanosized zirconium (hydrous) oxide particles of narrow size distribution is described. The procedure yields stable dispersions at low temperatures and short reaction times in the absence of surfactants, using inorganic zirconium salts. Crystal structure, particle size distribution, electrokinetic properties, stability, and thermal behavior of the prepared particles were investigated. Colloidal dispersions were treated with ultrasound to study its effect on the crystal structure of the calcined samples.

Order No.: JA712-017

(c) 1997 MRS
The effect of $\mathrm{Cr}$ and $\mathrm{La}$ on $\mathrm{MgTiO}_{3}$ and $\mathrm{MgTiO}_{3}-\mathrm{CaTiO}_{3}$ microwave dielectric ceramics

V.M. Ferreira*, F. Azought, R. Freer ${ }^{+}$, J.L. Baptista*

( ${ }^{*}$ Universidade de Aveiro, + University of Manchester/UMIST)

Magnesium titanate and $\mathrm{MgTiO}_{3}-\mathrm{CaTiO}_{3}$ ceramics were prepared by a chemical (Pechini) route and classical mixed oxide route. Selected specimens were doped with $\mathrm{Cr}$ or La. Specimens were sintered at $1350^{\circ} \mathrm{C}$ and $1400^{\circ} \mathrm{C}$. Microstructures were examined by optical microscopy, scanning electron microscopy and transmission electron microscopy. Dielectric properties were determined at $8 \mathrm{GHz}$ by the Hakki and Coleman method. The highest $Q$ values were obtained for undoped, chemically-prepared $\mathrm{MgTiO}_{3}$ (20800); any dopants caused the $\mathrm{Q}$ value to be degraded. Additions of small amounts of $\mathrm{Cr}(\leq 1 \mathrm{~mol} \%)$ to mixed oxide magnesium titanate increased the density to $97.1 \%$ theoretical, and increased the $Q$ value (from 7000) to 13000 . Additions of La led to the formation of $\mathrm{La}_{2} \mathrm{Ti}_{2} \mathrm{O}_{7}$ second phase and reduction in the $Q$ value for both materials. Both $\mathrm{Cr}$ and $\mathrm{La}$ acted as effective sintering aids, increasing density (to a maximum of $99 \%$ theoretical for $1 \%$ mol La in chemically prepared samples) and relative permittivity (to 18.1 for the same specimens).

The relative permittivity of $\mathrm{MgTiO}_{3}-\mathrm{CaTiO}_{3}$ ceramics increased with calcium content, but the corresponding $Q$ values decreased $\left(\varepsilon_{r}=\right.$ $19.9, \mathrm{Q}=8500$ for $\mathrm{Mg}: \mathrm{Ca}=94: 6$ ). Small additions of $\mathrm{La}$ to $\mathrm{Mg}$-Ca titanates enhanced the dielectric $Q$ values but decreased the relative permittivities. Order No.: JA712-018

(C) 1997 MRS

Alumina platelet reinforced reaction bonded aluminum oxide composites: Textured and random

L. An* S. Wu*, H.M. Chan*, M.P. Harmer*, D.G. Brandon+ ('Lehigh University, +The Technion-Israel Institute of Technology)

The reaction bonded aluminum oxide (RBAO) process and waterbased gel-casting were combined to produce alumina-platelet reinforced RBAO composites. In the RBAO process, a precursor powder mixture of $\mathrm{Al}$ metal and $\mathrm{Al}_{2} \mathrm{O}_{3}$ is reacted to form $100 \%$ ceramic. To obtain composites in which the platelets are highly aligned, tapes consisting of $10 \mathrm{vol} \%$ homogeneously distributed alumina-platelets and 90 vol\% RBAO precursor powder were made by water-based gel-casting using an extended doctor blade arrangement. Pellets of textured composites were subsequently prepared by stacking sheets cut from the green tapes and filter-pressing. Randomly oriented platelet composites were made using the same starting powders and gelling procedure, but without the tape-casting step. Reaction-bonding was carried out in a box furnace in air. Microstructures of the composites were characterized using $x$-ray diffraction (XRD) and scanning electron microscopy (SEM). The effect of platelet orientation on contact damage behavior was studied using a Hertzian indentation method. It was found that the textured composite exhibited improved damage resistance compared to the random composite.

Order No.: JA712-019

(C) 1997 MRS

Failure behavior of alumina and alumina/silicon carbide nanocomposites with natural and artificial flaws

F. Meschke, P. Alves-Riccardo, G.A. Schneider, N. Claussen (Technische Universität Hamburg-Harburg)

Alumina/silicon carbide nanocomposites with 5 vol\% SiC nanoparticles were produced by slip casting, pressureless sintering and hot isostatic pressing. The grain size dependencies of both the bend strength and fracture toughness have been investigated. The strength exceeds $1 \mathrm{GPa}$ at a grain size of $1.7 \mu \mathrm{m}$. Crack opening displacements (COD) were measured revealing that crack tip toughness is considerably lower than in pure alumina and an R-curve behavior is unlikely to occur. By introducing artificial pores with a size of $60 \mu \mathrm{m}$, the micromechanical fracture process has been studied in both pure alumina and nanocomposites. In contrast to alumina, where an annular precrack forms prior to fracture, it is suggested that precrack formation is strongly impeded in the nanocomposites and failure is controlled by microcrack initiation. The high strength of $\mathrm{Al}_{2} \mathrm{O}_{3} / \mathrm{SiC}$ nanocomposites seems to be the result of an unusually high crack initiation stress.

Order No.: JA712-020

(c) 1997 MRS 
Ag:Sb and Sb:Ag implantations into high purity silica

T.S. Anderson*, R.H. Magruder III*, D.L. Kinser*, J.E. Wittig*, R.A. Zuhr+, D.K. Thomas ${ }^{+}$

( ${ }^{*}$ Vanderbilt University, + Oak Ridge National Laboratory)

Silica composites containing nanometer dimension colloids have been fabricated by implantation of $\mathrm{Ag}$ ions followed by Sb ions, and by implantation of $\mathrm{Sb}$ ions followed by $\mathrm{Ag}$ ions. Doses for the sequential element implantations were in ratios of 9:3 $\mathrm{Ag}: \mathrm{Sb}$ and $3: 9 \mathrm{Sb}: \mathrm{Ag}$ with the total dose held constant at $12 \times 10^{16}$ ions $/ \mathrm{cm}^{2}$. Energies of implantation were $305 \mathrm{keV}$ for the $\mathrm{Ag}$ ions and $320 \mathrm{keV}$ for the $\mathrm{Sb}$ ions. Single element colloids were also fabricated by implantation of $\mathrm{Ag}$ or Sb using the same nominal dose and implantation energy of the sequential implantations. Approximately spherical particles were formed in all implanted samples. Microstructures of the nanoclusters in the various samples were markedly different. Selected area diffraction techniques revealed that alloyed phases of $\mathrm{Ag}-\mathrm{Sb}$ were formed in some of the sequential implantations. The microstructure and the optical response of the nanocluster glass composites were found to be strongly dependent upon the order of the ion species implanted. The optical spectra of the 3:9 Sb:Ag sample displays two resonance peaks indicative of an $\mathrm{Ag}$ resonance peak and a resonance peak of an alloyed phase of $\mathrm{Ag}-\mathrm{Sb}$. Optical spectra for the 9:3 Ag:Sb sample displays two broad absorption peaks indicative of coated particles.

Order No.: JA712-021

(C) 1997 MRS

In situ formation of $\mathrm{MoSi}_{2}$-SiC through reaction of $\mathrm{SiO}_{2}$ or $\mathrm{Si}_{3} \mathrm{~N}_{4}$ with Mo and carbon

R.V. Krishnarao, V.V. Ramarao, Y.R. Mahajan

(Defence Metallurgical Research Laboratory)

Composite powders of molybdenum silicide-SiC were synthe-

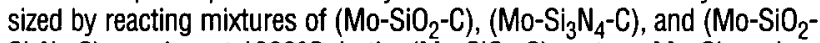

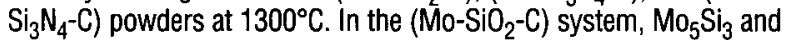

$\mathrm{Mo}_{3} \mathrm{Si}$ formed predominantly. $\mathrm{MoSi}_{2}$ formed the major constituent of the reaction product from powder mixtures containing $\mathrm{Si}_{3} \mathrm{~N}_{4}$. Vapor-solid $\mathrm{SiC}$ whiskers formed in the $\left(\mathrm{Mo}^{-} \mathrm{SiO}_{2}-\mathrm{C}\right)$ system. Vapor-liquid-solid whiskers of $\mathrm{SiC}$ and $\mathrm{Mo}_{5} \mathrm{Si}_{3} \mathrm{C}$ formed in $\left(\mathrm{Mo}^{2} \mathrm{SiO}_{2}-\mathrm{Si}_{3} \mathrm{~N}_{4}-\mathrm{C}\right)$ and $\left(\mathrm{Mo}_{0}-\mathrm{Si}_{3} \mathrm{~N}_{4}-\mathrm{C}\right)$ systems, respectively. The mechanism of formation of the VLS whiskers and molybdenum silicides was identified as: initially a thin layer of $\mathrm{Mo}_{2} \mathrm{C}$ forms on a Mo particle, the Si vapor from thermal decomposition of $\mathrm{Si}_{3} \mathrm{~N}_{4}$ deposits on the $\mathrm{Mo}_{2} \mathrm{C}$ surface and forms a droplet of ternary "Nowotny phase" $\mathrm{Mo}_{<5} \mathrm{Si}_{3} \mathrm{C}_{<1}$, and $\mathrm{a} \mathrm{SiC} / \mathrm{Mo}_{5} \mathrm{Si}_{3} \mathrm{C}$ whisker is formed by nucleation and growth from the supersaturated ternary phase. After reaction with the $\mathrm{MO}_{2} \mathrm{C}$ layer, the SiO/Si vapor also reacts with the Mo particle to form a bulk of silicides.

Order No.: JA712-022

C 1997 MRS

\section{A descriptive model linking possible formation mechanisms for} graphite-encapsulated nanocrystals to processing parameters B.R. Elliott*, J.J. Host*, V.P. Dravid*, M.H. Teng ${ }^{+}$, J-H. Hwang ${ }^{*}$

( ${ }^{*}$ Northwestern University, + National Taiwan University)

New and modified mechanisms are proposed to account for detailed observations of carbon encapsulation of $\mathrm{Fe}, \mathrm{Ni}$, and $\mathrm{Co}$ nanocrystals. The mechanisms are based on aerosol and gas phase chemistry and on the catalytic effects of transition metals. Two parameters are found to qualitatively dominate production: the local-path carbon-to-metal ratio (LCM) and the global carbon-to-metal ratio (GCM). LCM's select which mechanisms are active along each pathway within the reactor. The GCM places bounds upon and determines the weighting between different LCM's and thus determines the distribution of different nanoscale products within the collected, macroscopic product. A two part processing parameter $\rightarrow$ mechanism $\rightarrow$ product map links the components. The generality of the model is discussed throughout with reference to related processes and the encapsulation of other materials.

Order No.: JA712-023
The mechanical behavior of a passivating surface under potentiostatic control

D.F. Bahr, J.C. Nelson, N.I. Tymiak, W.W. Gerberich

(University of Minnesota)

Continuous microindentation has been carried out on an iron-3\% silicon single crystal in $1 \mathrm{M}$ sulfuric acid. The ability of the material to support elastic loading is directly linked to the presence of thermally grown oxide films and passive films applied through potentiostatic control of the sample. When the passive film is removed, either by chemical or electrochemical means, the iron alloy can no longer sustain pressures on the order of the theoretical shear strength of iron. Instead, the metal behaves in a traditional elastic-plastic manner when no film is present. The oxide film at the edges of the indentation can sustain applied tensile stresses up to $1.2 \mathrm{GPa}$ prior to failure. Indentation in materials undergoing dissolution must account for the rate of material removal over the remote surface and the resulting plastic deformation around the contact of the indentation. Order No.: JA712-024

(C) 1997 MRS

Insights into the ion-assisted nucleation of diamond on silicon S.P. McGinnis, M.A. Kelly, S.B. Hagström (Stanford University )

The ion-assisted nucleation of diamond was studied in a microwave plasma chemical vapor deposition system to gain insights into the processes controlling this phenomenon. The dependence of the nucleation density on bias voltage and temperature, as well as experiments with an electrically-isolated substrate, are consistent with an ion bombardment mechanism for diamond nucleation. However, the growth of these nuclei is dominated by neutral species rather than ions. Measurements of the bias current under various conditions also provide details on the roles of the incident ion flux and substrate electron emission during this process. Furthermore, Monte Carlo simulations of the ion energy distribution at the substrate are compared to experimental measurements. Preferential sputtering, thermal spike, and carbon subplantation nucleation mechanisms are assessed based on the experimental and modeling results.

Order No.: JA712-025

(C) 1997 MRS

Interdiffusions and reactions in $\mathrm{Cu} / \mathrm{TiN} / \mathrm{Ti} / \mathrm{Si}$ and $\mathrm{Cu} / \mathrm{TiN} / \mathrm{Ti} / \mathrm{SIO}_{2} / \mathrm{Si}$ multilayer structures

S-K. Rha*, W-J. Lee*, S-Y. Lee*, D-W. Kim+, C-0. Park*, S-S. Chun ${ }^{*}$ ("Korea Advanced Institute of Science and Technology,

+Kyonggi University)

Sputtered TiN(30-120 nm thick)/Ti(30 nm thick) films were studied as a diffusion barrier between silicon substrate and copper films. The effects of TiN thickness and the existence of $\mathrm{SiO}_{2}$ layer between $\mathrm{Ti}$ and silicon substrate on the diffusion barrier property were investigated using various characterization methods. The copper diffusion barrier property of TiN/Ti was found to be affected not only by the TiN thickness, that is diffusion distance, but also by the microstructure of the TiN, which changes with the thickness of $\mathrm{TiN}$ film. The existence of the $\mathrm{SiO}_{2}$ layer enhanced the diffusion barrier property of $\mathrm{TiN} / \mathrm{Ti}$. This is because the $\mathrm{SiO}_{2}$ layer between $\mathrm{Ti}$ and $\mathrm{Si}$ inhibited the formation of titanium silicides, so Ti layer was available to be used as the sacrificial diffusion barrier for copper.

Order No.: JA712-026

(c) 1997 MRS

\section{Diamond nucleation on smooth $\mathrm{Si}_{3} \mathbf{N}_{4}$-coated substrate \\ N. Xu, Z. Zheng, Y. Du}

(Fudan University)

Diamond was deposited on smooth $\mathrm{Si}_{3} \mathrm{~N}_{4}$ coated Si-substrates using hot-filament chemical vapor deposition (CVD). Prior to diamond deposition, the substrates were pretreated under high temperature $\left(700-900^{\circ} \mathrm{C}\right)$ by decomposed pure hydrogen. The experimental results show that these pre-growth processes at a substrate temperature of 
$850^{\circ} \mathrm{C}$ enhanced the diamond nucleation on $\mathrm{Si}_{3} \mathrm{~N}_{4}$. This indicated that decomposed hydrogen acted to the substrate to produce active centers $(<100 \mathrm{~nm})$, which were promotive for diamond nucleation. It has also been suggested that $\mathrm{Si}_{3} \mathrm{~N}_{4}$ coating can inhibit the carbon transport into substrate, and it is beneficial to the diamond nucleation.

Order No.: JA712-027

(C) 1997 MRS

\section{Pulsed laser deposition of carbon nitride thin films in nitrogen gas} ambient

M. Okoshi, H. Kumagai, K. Toyoda

(The Institute of Physical and Chemical Research-RIKEN)

Carbon nitride thin films have been successfully deposited by ablating a graphite target $(99.999 \%)$ in nitrogen gas ambient using the second $(532 \mathrm{~nm})$ or third $(355 \mathrm{~nm})$ harmonic of a Q-switched Nd:YAG laser. Carbon nitride films consisting of approximately $40 \%$ nitrogen were obtained at $7.5 \times 10^{-3} \mathrm{~Pa}$ of nitrogen gas pressure using the third harmonic laser. The $\mathrm{C}-\mathrm{N}$ chemical bond in the films was observed by $\mathrm{X}$-ray photoelectron spectroscopy and Fourier transform infrared spectroscopy. Ellipsometric studies revealed that the refractive index of the fabricated films decreased with increasing nitrogen concentration.

Order No.: JA712-028

(C) 1997 MRS

A study on magnesium diffusion into $\mathrm{LiNbO}_{3}$ single crystal by $\mathrm{x}$-ray diffraction, differential thermal analysis and scanning electron microscopy

W. Que*, S. Lim*, X. $\mathrm{YaO}^{+}, \mathrm{A}$.Q. Liü

( National University of Singapore, +Xi'an Jiaotong University,

"Defence Science Organisation)

The diffusion of magnesium into lithium niobate single crystal under different diffusion conditions has been studied by $x$-ray diffraction, glancing-incidence $x$-ray diffraction, differential thermal analysis and scanning electron microscopy in an attempt to determine the diffusion mechanism and evaluate the crystallinity of the diffused layer. It is found that the magnesium diffused layer exhibits the crystal structure of an unknown compound from the $\mathrm{Mg}-\mathrm{Li}-\mathrm{Nb}-0$ ternary system and $\mathrm{MgNb}_{2} \mathrm{O}_{6}$. The $\mathrm{MgNb}_{2} \mathrm{O}_{6}$ is in the surface layer of the magnesium diffused layer, while the unknown compound is in the subsurface layer beneath the $\mathrm{MgNb}_{2} \mathrm{O}_{6}$. It is proposed that this unknown compound and $\mathrm{MgNb}_{2} \mathrm{O}_{6}$ which form during a solid state reaction between a thin layer of $\mathrm{MgO}$ and a lithium niobate crystal in a $\mathrm{Li}_{2} \mathrm{O}$-rich atmosphere are the real sources for $\mathrm{Mg}$-ion indiffusion into lithium niobate crystal. The changes in Curie temperature with diffusion parameters are noted. Reasons of lattice distortion and mechanisms of $\mathrm{Mg}$-ion indiffusion are discussed and analyzed.

Order No.: JA712-029

(C) 1997 MRS

Please use the convenient postcard located in the back of the MRS Bulletin to order JMR reprints. When ordering single article reprints please note

they are not available until the issue is published. See JMR Abstracts on the MRS Website at http://www.mrs.org/publications/jmr/jmra/.
Influence of nanostructure size on the luminescence behavior of silicon nanoparticle thin films

A.A. Seraphin, E. Werwa, K.D. Kolenbrander

(Massachusetts institute of Technology)

We demonstrate the effect of particle size and quantum confinement on the luminescence properties of nanoscale silicon thin films. Thin films of agglomerated silicon nanoparticles are synthesized using pulsed laser ablation supersonic expansion. Following deposition, standard semiconductor processing techniques are employed to reduce the nanoparticle size. Films are oxidized both in air and chemically to reduce the silicon core dimensions, resulting in a shift of the luminescence emission peak to shorter wavelengths. Removal of the oxide using hydrofluoric acid (HF) results in further blueshifting of the luminescence, as does subsequent re-oxidation in air, and using nitric acid. The luminescence properties of samples are also studied as a function of excitation intensity. For room temperature excitation with a pulsed $355 \mathrm{~nm}$ source, a saturation of the photoluminescence intensity at high excitation intensity is observed, along with a blueshift of the peak PL wavelength. This behavior is found to persist at reduced temperature. A saturation of PL intensity, but no blueshift, is observed for high excitation intensity using a cw $488 \mathrm{~nm}$ source at room temperature. At reduced temperatures, no saturation of emission intensity occurs for high intensity $488 \mathrm{~nm}$ cw excitation. Both the irreversible shifting of the peak PL wavelength with size reducing treatments and the PL behavior at high excitation intensities indicate that quantum confinement determines the luminescence wavelength.

Order No.: JA712-030

(C) 1997 MRS

A novel polymer electrolyte based on oligo(ethylene glycol) 600 , $\mathrm{K}_{2} \mathrm{PdCl}_{4}$ and $\mathrm{K}_{3} \mathrm{Fe}(\mathrm{CN})_{6}$

V. Di Noto

(dell'Università degli Studi di Padova)

New electrolytic systems were prepared by reacting $\mathrm{K}_{3} \mathrm{Fe}(\mathrm{CN})_{6}$ and $\mathrm{K}_{2} \mathrm{PdCl}_{4}$ in a mixture of water and poly(ethylene glycol) 600 (PEG). The reaction occurs in two steps: first a gel is formed, which then shrinks, releasing the solvent. The product thus obtained has the consistency of a smooth, solid plastic paste and is very stable. The influence of the reaction mixture on the structure, morphology and conductivity of the products was investigated carrying out three preparations (I, II, III) at increasing ratio PEG $600 / \mathrm{H}_{2} \mathrm{O}$. By FT-IR studies and analytical data it was concluded that these materials are inorganic-organic networks containing $\mathrm{CN}$ bridges between $\mathrm{Fe}$ and $\mathrm{Pd}$ atoms and PEG 600 bridges between Pd atoms. Scanning electron microscopy studies revealed that the morphology of polymers I, II, and III are significantly influenced by the conditions of the synthesis. Conductivity measurements made at different temperatures showed that polymers I, II, and III conduct ionically. The conductivity of polymer I, which was synthesized with the highest water/PEG 600 ratio, is on the order of $1.4 \cdot 10^{-3} \mathrm{~S} / \mathrm{cm}$ at $25^{\circ} \mathrm{C}$.

Order No.: JA712-031

(C) 1997 MRS

\section{FUTURE MATERIALS RESEARCH SOCIETY MEETINGS}

\section{Spring Meeting: April 13-17 Exhibit: April 14-16 San Francisco, California}

\section{Meeting Chairs}

John A. Emerson, Sandia National Laboratories, 505-845-9747; fax 505-844-2894; jaemers@sandia.gov

Ronald Gibala, University of Michigan, 313-936-0178;

fax 313-763-4788; rgibala@umich.edu

Caroline A. Ross, Massachusetts Institute of Technology,

617-258-0223; fax 617-252-1020; caross@mit.edu

Leo J. Schowalter, Rensselaer Polytechnic Institute,

518-276-6435; fax 518-276-6680; schowalt@unix.cie.rpi.edu
1998 Fall Meeting, November 30-December 4

Exhibit: December 1-3

Boston, Massachusetts

Meeting Chairs

Clyde L. Briant, Brown University, 401-863-2626; fax 401-863-7677; clyde_briant@brown.edu

Eric H. Chason, Sandia National Laboratories, 505-844-8951;

fax 505-844-1197; ehchaso@sandia.gov

Howard E. Katz, Bell Laboratories, Lucent Technologies, 908-582-6968; fax 908-582-3609; hek@bell.com

Yuh Shiohara, ISTEC, SRL, 81-3-3536-5710; fax 81-3-3536-5717; shiohara@istec.or.jp 